\title{
Lifestyle interventions are feasible in patients with colorectal cancer with potential short-term health benefits: a systematic review
}

\author{
Susan J. Moug ${ }^{1}$ - Adam Bryce ${ }^{2}$ - Nanette Mutrie ${ }^{3}$ • Annie S. Anderson ${ }^{4}$
}

Accepted: 11 March 2017 / Published online: 3 April 2017

(C) The Author(s) 2017. This article is published with open access at Springerlink.com

\begin{abstract}
Purpose Lifestyle interventions have been proposed to improve cancer survivorship in patients with colorectal cancer (CRC), but with treatment pathways becoming increasingly multi-modal and prolonged, opportunities for interventions may be limited. This systematic review assessed the evidence for the feasibility of performing lifestyle interventions in CRC patients and evaluated any short- and long-term health benefits.

Methods Using PRISMA Guidelines, selected keywords identified randomised controlled studies (RCTs) of lifestyle interventions [smoking, alcohol, physical activity (PA) and diet/excess body weight] in CRC patients. These electronic databases were searched in June 2015: Dynamed, Cochrane Database, OVID MEDLINE, OVID EMBASE, and PEDro. Results Fourteen RCTs were identified: PA RCTs $(n=10)$ consisted mainly of telephone-prompted walking or cycling interventions of varied durations, predominately in adjuvant setting; dietary/excess weight interventions RCTs $(n=4)$
\end{abstract}

Susan J. Moug

susanmoug@nhs.net

1 The University of Glasgow, Royal Alexandra Hospital, Corsebar Road, Paisley PA2 9PN, UK

2 The University of Glasgow, University Avenue, Glasgow G12 8QQ, UK

3 Physical Activity for Health Research Centre, Moray House School of Education, The University of Edinburgh, St. Leonard's Land, Holyrood Road, Edinburgh EH8 8AQ, UK

4 Centre for Public Health Nutrition Research, Division of Cancer Research, Ninewells Medical School, Level 7, Mailbox 7 , Dundee DD1 9SY, UK focused on low-fat and/or high-fibre diets within a multimodal lifestyle intervention. There were no reported RCTs in smoking or alcohol cessation/reduction. PA and/or dietary/excess weight interventions reported variable recruitment rates, but good adherence and retention/follow-up rates, leading to short-term improvements in dietary quality, physical, psychological and quality-of-life parameters. Only one study assessed long-term follow-up, finding significantly improved cancer-specific survival after dietary intervention.

Conclusions This is the first systematic review on lifestyle interventions in patients with CRC finding these interventions to be feasible with improvements in short-term health. Future work should focus on defining the optimal type of intervention (type, duration, timing and intensity) that not only leads to improved short-term outcomes but also assesses long-term survival.

Keywords Lifestyle interventions $\cdot$ Colorectal cancer $\cdot$ Patient outcomes

\section{Introduction}

The incidence of colorectal cancer (CRC) in the UK is increasing [1]. With neo-adjuvant and adjuvant multi-modal treatment pathways, complication risks and the possibility of a stoma, a patient's physical and psychological recovery can be prolonged, resulting in reduced short- and long-term quality of life [2]. Additionally, recurrent disease will be diagnosed in $\geq 30 \%$ leading to poorer long-term survival [1,2]. Therefore, there is a clear need to develop effective strategies that could improve the quality and duration of survivorship in CRC patients.

One such strategy is lifestyle interventions. The World Cancer Research Fund, The European Code against Cancer 
and The International Agency for Research into Cancer have presented a body of evidence demonstrating that almost a third of cancers can be prevented by improving the key lifestyle factors of excess weight, poor diet, smoking, alcohol excess and physical inactivity [1-6]. In addition, there is evolving observational and interventional evidence that modifying these factors can lead to improved peri-operative outcomes and, in the short-term, better quality of life for patients with cancer [7-14].

Lifestyle interventions can be methodologically complex, especially if more than one lifestyle factor is being assessed. As a consequence, the majority of work has been carried out in other cancer populations rather than CRC, which, with its multi-modal treatment options, can make the performing of randomised controlled trials (RCTs) difficult $[11,14]$. To date, it is uncertain if RCTs on lifestyle interventions are feasible and/or beneficial in CRC populations.

This systematic review aims to collate the published evidence for the feasibility of performing lifestyle interventions in patients with CRC, allowing conclusions on the short- and long-term health benefits to be drawn.

\section{Materials and methods}

The study was developed according to the PRISMA Guidelines [15], with guidance from the Cochrane Collaboration Handbook [16] using the PICO framework [17]. The protocol was registered on PROSPERO (CRD42015017205) [18].

\section{PICOS}

Participants: adults $\geq 18$ years of age with non-metastatic CRC.

Interventions: modification of $\geq 1$ lifestyle factor (weight, diet, physical activity [PA], smoking and alcohol).

Primary outcomes: to assess feasibility of performing lifestyle interventions in CRC patients (e.g. recruitment, adherence and follow-up/retention rates)

Secondary outcomes: summarise any documented short (e.g. quality-of-life measurements) and long-term health outcomes (e.g. cancer recurrence, cancer-specific survival)

Study design: randomised controlled trials (RCTs)

\section{Search strategy}

In June 2015, a clinical librarian searched the following databases to identify relevant publications: Dynamed, Cochrane Database of Systematic Reviews, OVID MEDLINE, OVID EMBASE, PEDro. Keywords used are the following: colon cancer, rectal cancer, colorectal cancer, obesity, diet, excess weight, smoking, alcohol, physical activity, exercise, randomised controlled trials, systematic reviews, lifestyle factors, lifestyle intervention, recurrence, disease-free survival, overall survival, short-term outcomes, long-term outcomes. Exclusion keywords were: risk factors, screening uptake, screening awareness. Clinicaltrials.gov website was searched for relevant registered trials. There were no restrictions on date or language of publication. Expert opinions, letters and comments were excluded.

\section{Screening and data extraction}

The resultant citations (abstracts) were independently examined with duplicates removed (SJM and AB). After screening, the full text was obtained and those papers independently assessed for eligibility, with attention paid to reference lists of reviews. Each reviewer then independently allocated relevant papers to the four lifestyle factor sections: alcohol, diet/ excess weight, PA and smoking. A paper could be allocated to more than one section if more than one lifestyle factor was assessed. For further information, the authors were contacted by e-mail and any reviewing disagreements were resolved by discussion or by conferring with one further reviewer (ASA or NM).

\section{Assessment of methodological quality}

The Jadad scale [19] was applied to each paper to assess the methodological quality of the included trials. The quality scale involved three items: randomization, double blinding and withdrawals or dropout. The score ranged from 0 to 5: 0-2 for randomization, $0-2$ for blinding and $0-1$ for withdrawals or dropout, with a score of 2 or less considered methodologically poor [20]. Data were collected independently by the two reviewers and crosschecked.

\section{Results}

One hundred fourteen papers were identified after the literature search (Fig. 1). After searching the references of systematic reviews and meta-analyses, a further 14 papers were added. On review of the abstracts, 69 papers were excluded, leaving 59 full papers that were read with four additional papers found.

At the end of identification, screening and eligibility, there were no published RCTs on performing interventions in smoking and alcohol reduction/cessation, 10 RCTs in PA (14 published papers) and 4 RCTs in diet/excess weight (6 published works) [Tables 1, 2, 3 and 4]. 
Fig. 1 Flow diagram for the study selection process (PRISMA)

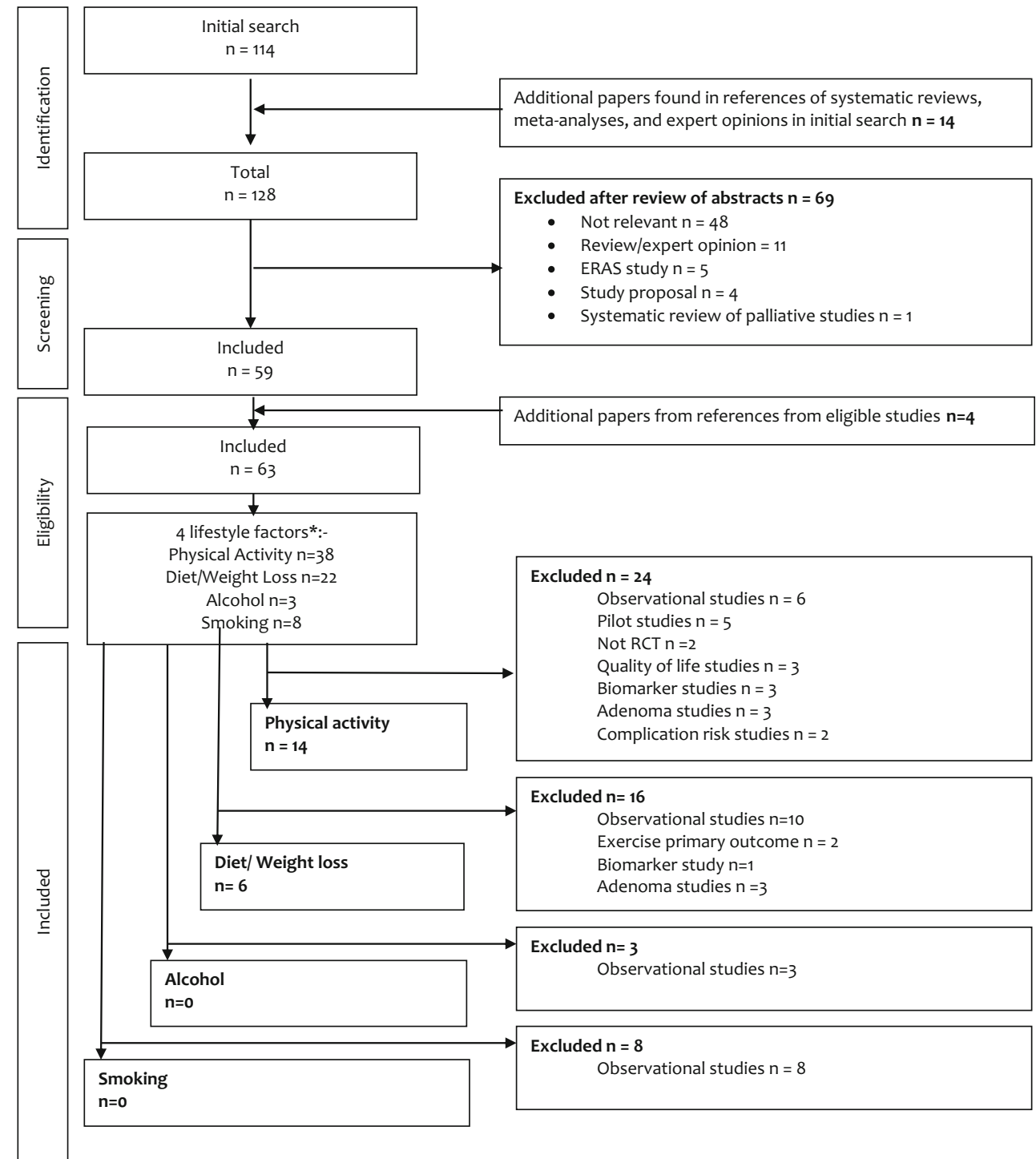

* total adds up to 71 papers as 8 papers were considered in 2 different lifestyle factor sections.

\section{Physical activity and colorectal cancer}

The 14 publications on physical activity (PA) intervention are mainly from North America, published from 2003 onwards, with the majority being: multi-centred in design, Jadad score 3 , telephone-guided home/outpatient-based physical activities (cycling, walking) and performed as rehabilitation (adjuvant) rather than pre-habilitation (neo-adjuvant) (Tables 1 and 2). Recruitment rates vary, adherence is reasonable (range 67 to $81.4 \%$ ) and follow-up/retention rates are reported as at least $80 \%$ in the majority of studies. Improvements in fatigue, physical activity parameters (e.g. 6-min walk test distance, submaximal fitness test and lower extremity function) and overall quality of life were documented in interventions ranging from
4 to 12 months. No study assessed cancer-free or overall survival $[21-33,36]$.

\section{Pre-habilitation in colorectal cancer patients}

With the success of enhanced recovery after surgery programmes that focus on early mobility after surgery [37], researchers assessed pre-operative PA interventions ('pre-habilitation'). The two published studies support the feasibility of performing a pre-operative physical activity intervention in patients with $\mathrm{CRC}$; however, both studies contained mixed benign and malignant populations [23, 29]. In addition, colonic cancer accounted for the majority of CRC patients recruited. The exercise intervention was stationary cycling in both 


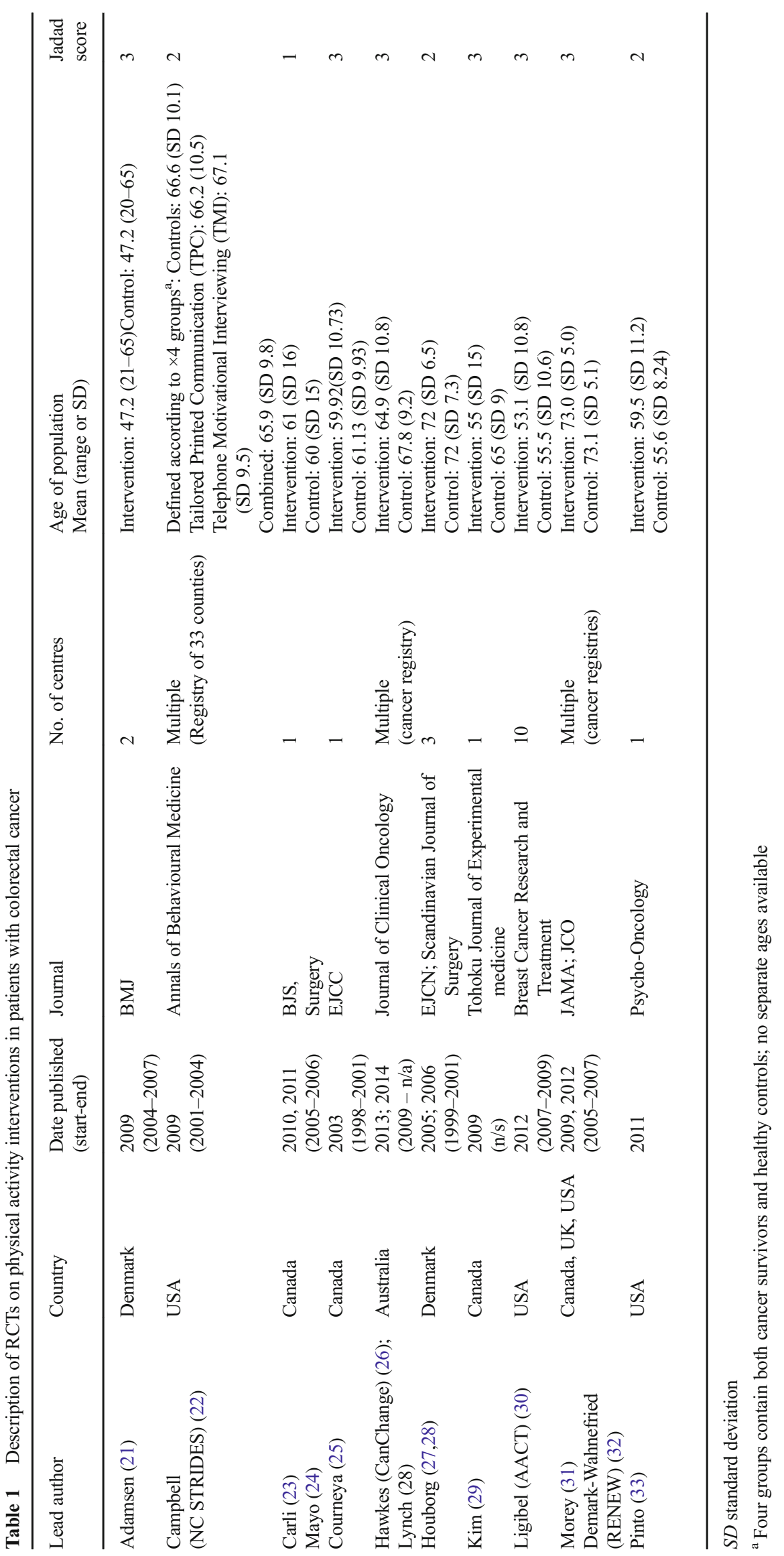


Table 2 Aims and outcomes of RCTs on physical activity interventions in patients with colorectal cancer

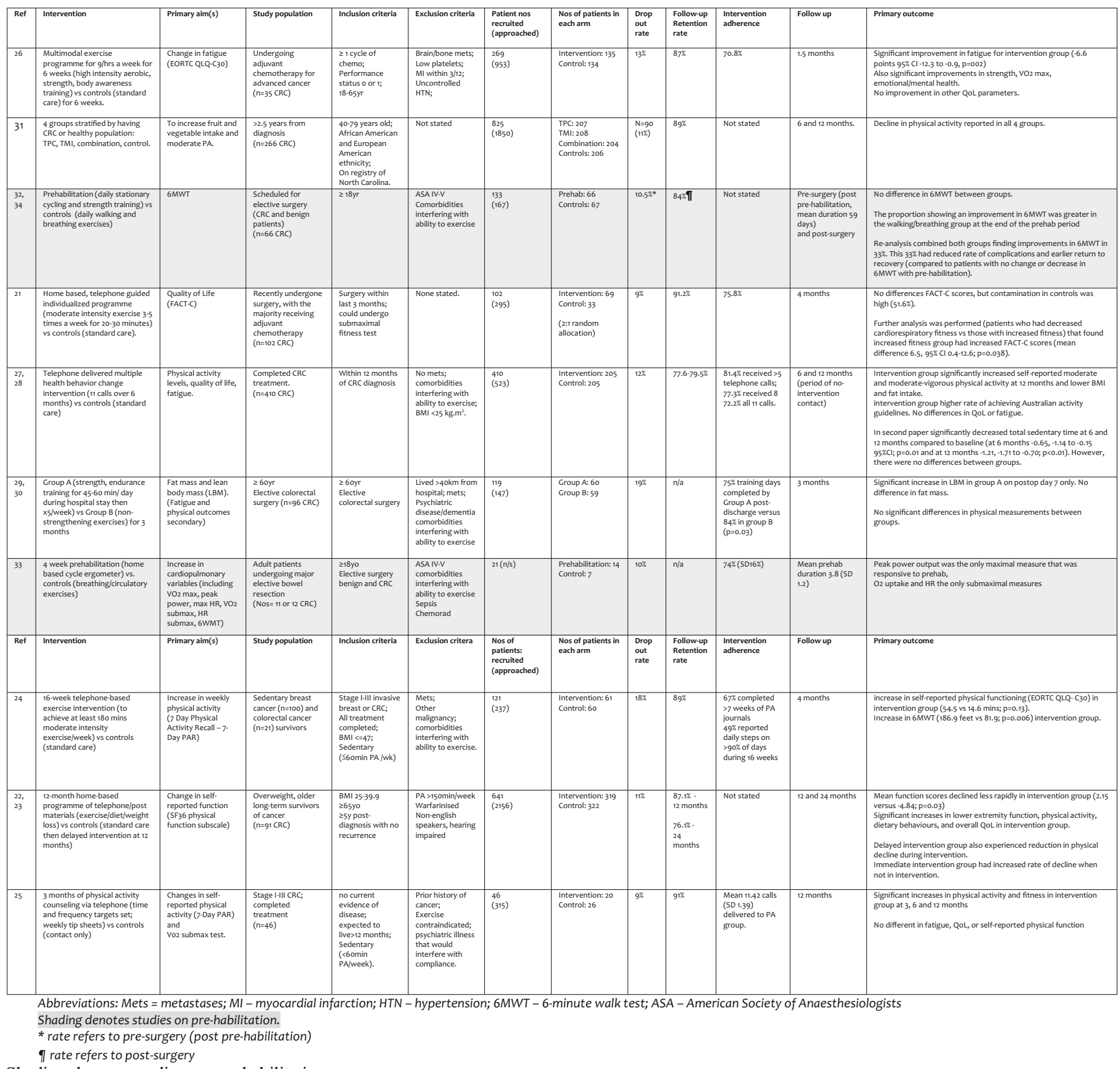

Shading denotes studies on pre-habilitation

Mets metastases, $M I$ myocardial infarction, HTN hypertension, 6MWT 6-min walk test, ASA American Society of Anaesthesiologists

${ }^{a}$ Rate refers to pre-surgery (post pre-habilitation)

${ }^{\mathrm{b}}$ Rate refers to post-surgery

studies with mean duration of intervention completed 7.4 and 3.8 weeks respectively. Low dropout rates were reported (10.5 and $26 \%$ with one study reporting an $84 \%$ follow-up rate, suggesting the interventions are tolerated well by patents. In relation to physical fitness improvements after the cycling intervention, one study reported no differences in 6-min walk test (6MWT) between groups at the two time points tested: pre-surgery (at the end of pre-habilitation) or post-surgery [mean 9.6 weeks, SD 3.4] [23]. In comparison, the other study found significantly improved cardiorespiratory function with an increased peak power (26\% increase versus $0 \%$ in controls), reduced heart rate and oxygen uptake in their intervention group only [29]. It is possible that the study of Carli et al. was contaminated by their control group, increasing their 6MWT (pre-habilitation $-10.6 \mathrm{~m}$ versus controls $+8.7 \mathrm{~m}$ ), a phenomenon described by Courneya et al. in 2003, where controls can be indirectly incentivised to exercise more [25]. Alternatively, the authors argued that the controls were not an 


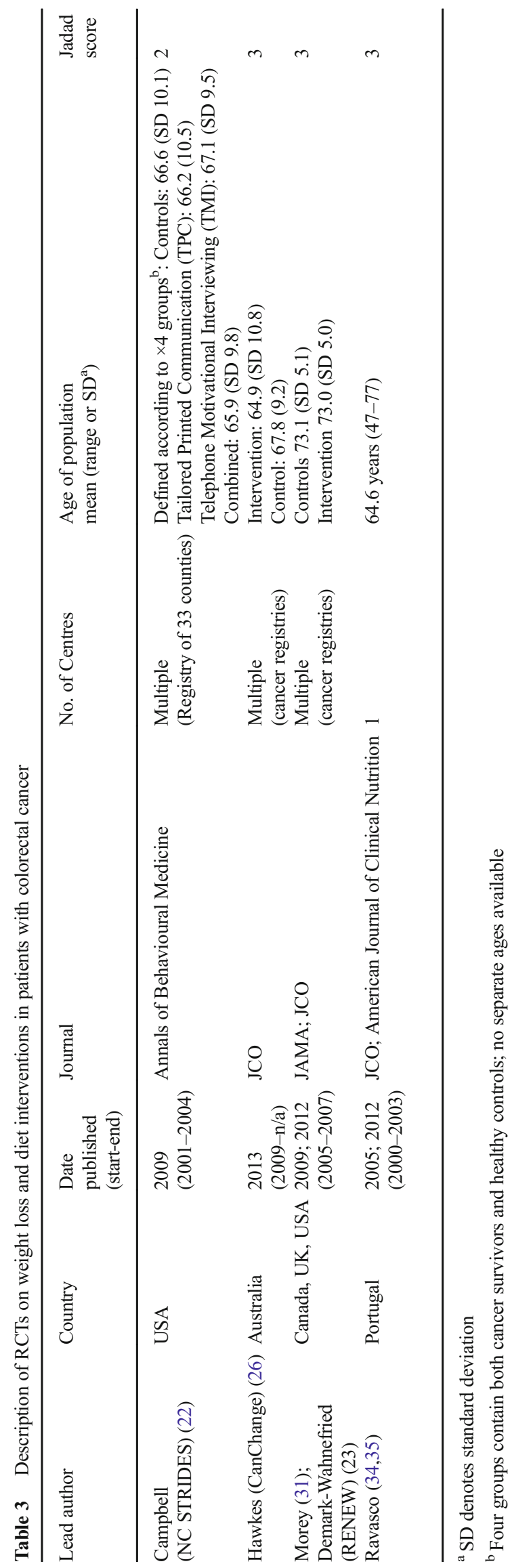

optimal comparative group as their walking programme encouraged a minimum of $30 \mathrm{~min} /$ day, which means many will have achieved more than the weekly recommended UK guidelines for PA [38]. As a result, this group went on to re-analyse their data, combining the two groups to determine the overall affect of pre-habilitation on 6WMT, finding increases in 33\%, no change in $38 \%$ and decreases in $29 \%$ [24]. These results translated in to significantly improved re-operative rates $(29 \%$ in those that had deteriorated compared to the increased or no change groups combined, 18 and $2 \%$ respectively) and earlier recovery to baseline function 2-4 months after undergoing surgery (32 versus 77 versus 59\%).

\section{Post-treatment PA interventions in colorectal cancer patients}

This is the lifestyle area where most research has been performed. Courneya et al. (2003) published the first RCT assessing PA intervention in CRC survivors (74\% colon cancer) that had completed their treatment at least 3 months previously [25]. For approximately 16 weeks, patients were randomised to a home-based exercise programme (cycling, swimming or walking) and weekly telephone calls whilst the controls received no exercise prescription but did receive weekly phone calls. Recruitment was only $35 \%$ with a high retention rate of $92 \%$, suggesting the intervention was well tolerated. At follow-up testing, there were no differences in QoL measurements or PA between groups (FACT-C mean difference $-1.3,95 \% \mathrm{CI}-7.8$ to $5.1, p=0.679$ ). In addition to the study not being powered, the authors proposed that contamination by the control group could explain the results (documented at 51.6\%) and explored this by performing an ancillary analysis comparing those patients that had increased physical fitness to those that had decreased. This time significantly improved QoL scores in the increased physical fitness group were found $(6.5,95 \%$ CI $0.4-12.6, p=0.038)$.

The next four trials support the findings of Courneya et al. with a home-based telephone-guided PA intervention [26, 30-33]. The patient populations vary with some containing mixed cancer populations, and it is not always stated what percentage of the CRC patients recruited had rectal cancer. The exact interventions vary and can contain aerobic and strength components, making direct comparisons between studies difficult. However, low dropout rates (9-19\%) with good adherence and retention rates suggest these interventions are feasible and well tolerated by CRC patients.

The majority of these studies have documented improvements in their physical parameters in CRC patients that had undergone adjuvant PA intervention. In the RENEW trial, older and overweight cancer survivors had significantly increased levels of activity, with the mean function scores and lower extremity function declining less rapidly in comparison to the control group that had delayed intervention after 
Table 4 Aims and outcomes of RCTs on weight loss and diet interventions in patients with colorectal cancer

\begin{tabular}{|c|c|c|c|c|c|c|c|c|c|c|c|c|}
\hline Ref & Intervention & Primary aim & $\begin{array}{l}\text { Study } \\
\text { Population }\end{array}$ & Inclusion criteria & Exclusion criteria & $\begin{array}{l}\begin{array}{l}\text { Nos of patients: } \\
\text { recurted } \\
\text { (approached) }\end{array}\end{array}$ & $\begin{array}{l}\begin{array}{l}\text { Nos patient in } \\
\text { each arm }\end{array} \\
\end{array}$ & $\begin{array}{l}\text { Drop out } \\
\text { rate }\end{array}$ & 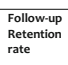 & $\begin{array}{l}\text { Intervention } \\
\text { adherence }\end{array}$ & Follow up & Primary Outcome \\
\hline 31 & 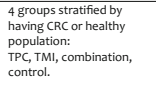 & 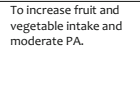 & 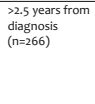 & 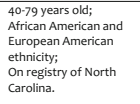 & Not stated & 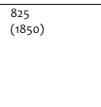 & $\begin{array}{l}\text { TCC:207 } \\
\text { TM: 2083 } \\
\text { Combintion: } 204 \\
\text { Controlis: 206 }\end{array}$ & 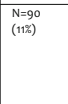 & $89 \%$ & Not stated & 6 and 12 months. & 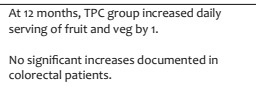 \\
\hline 27 & 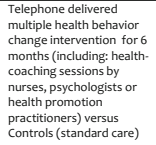 & $\begin{array}{l}\text { Physical activity levels, } \\
\text { quality of life, fatigue. } \\
\text { Secondary aim: BMl; } \\
\text { dietary intake of fat, } \\
\text { fiber, frut } \\
\text { vegand }\end{array}$ & $\begin{array}{l}\text { Completed } \\
\text { CRC } \\
\text { treatment. } \\
(n=410 \text { CRC) }\end{array}$ & $\begin{array}{l}\text { Whthinit month of } \\
\text { CRC diggnosis }\end{array}$ & 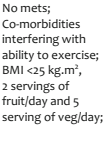 & $\begin{array}{l}410 \\
(523) \\
(10)\end{array}$ & $\begin{array}{l}\text { Interentition: } \\
\text { control } 205\end{array}$ & $12 \%$ & $77.6-79.5 \%$ & 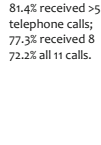 & 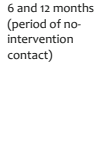 & 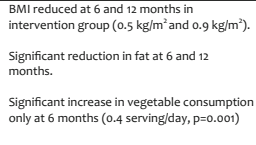 \\
\hline $\begin{array}{l}22, \\
23\end{array}$ & 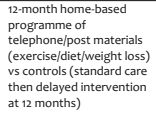 & 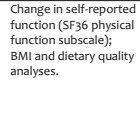 & 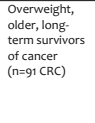 & 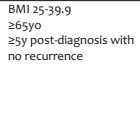 & 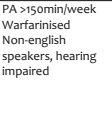 & $\begin{array}{l}\begin{array}{l}641 \\
(2156) \\
\mathrm{n}=91 \mathrm{CRC}\end{array} \\
\end{array}$ & $\begin{array}{l}\text { Interenention: } 319 \\
\text { Control: } 322\end{array}$ & $11 \%$ & 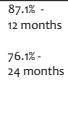 & Not stated & 12 and 24 months & 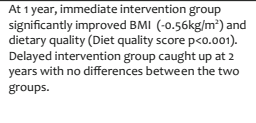 \\
\hline $\begin{array}{l}37, \\
38\end{array}$ & 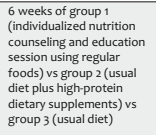 & $\begin{array}{l}\text { Analysis of the long. } \\
\text { tetum effect of of } \\
\text { nutrtitionaldetry } \\
\text { interventions on } \\
\text { patients }\end{array}$ & $\begin{array}{l}\text { RCC patients } \\
(n=111)\end{array}$ & $\begin{array}{l}\text { Undergoing neo- } \\
\text { adiuvartradiotherapy, } \\
\text { then surargery then } \\
\text { adiuvant } \\
\text { chemotherapy. }\end{array}$ & Not stated & (n) & 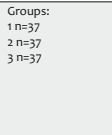 & $0 \%$ & $80 \%$ & Not stated & 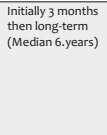 & 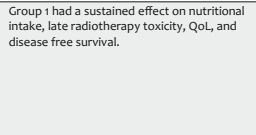 \\
\hline
\end{tabular}

Shading represents study on long-term outcomes in CRC patients.

Shading represents study on long-term outcomes in CRC patients

12 months [31, 32]. At 2-year follow-up, the rate of decline in physical function had significantly slowed (seen in both the immediate and delayed intervention groups), but increased in the year after the intervention finished in the immediate group, displaying a protective effect of PA. Other studies have reported improved 6MWT (increased by $186.9 \mathrm{ft}$ versus 81.9 in controls, $p=0.006$ ), VO2 max (mean difference $0.16 \mathrm{~L} / \mathrm{min}$, $95 \%$ CI $0.1-0.2 ; p<0.001)$ and leg press strength $(29.7 \mathrm{~kg}$, 23.4 to $34.9, P<0.0001)$ [30, 33]. In addition, one study reported improved fatigue levels in the intervention group (EORTC QLQ C20; -6.6 points, 95\% CI -12.3 to -0.9 ; $p=0.02)$. [30, 33]. At 1 year, the intervention group had.

The most recent publication on one of the largest powered trials on colon cancer participants found increased time in moderate PA at 12 months (30 min a day more; $p=0.003$ ) [26]. In addition, the intervention group was more likely to achieve the Australian Physical Activity Recommendations (16.4 versus $9.2 \%$; $p=0.047$ ). Within the telephone counselling, advice was given about 'limiting sedentary habits such as watching television', and further work from this group found reduced sedentary time in both groups, but this difference was not significant [36]. However, a subgroup analysis found only the intervention group decreased sedentary time at 12 months in the $>60$ years of age, male and non-obese. The remaining three papers did not report any beneficial outcomes with adjuvant PA interventions in CRC patients which may reflect the different PA interventions. One group started in hospital training (walking on ward, stair climbing and strength training) that continued after discharge $(\times 5 /$ week $)[27,28]$. There were no differences between groups at 30 and 90 days after surgery in sit-to-stand test and 6MWT. The authors suggested that post-operative exercise is not beneficial in the CRC population, but this study's intervention was primarily based on strength exercises with the majority of the aerobic activity performed in the hospital to allow quick recovery of mobility post-operatively, rather than as part of a targeted progressive intervention.

The third paper that did not report improvements aimed to assess two different methods of promoting diet and PA: tailored print communication (TPC) only, telephone motivational interviewing (TMI) only, combination and controls [22]. Using self-reporting, the authors found that none of the four groups had an increase in PA at 1 year follow-up. This study was not powered, and the health behaviour interventions had substantially less patient contact compared to the other RCTs (e.g. TMI consisted of quarterly calls versus biweekly calls by CanChange) [26].

\section{Diet and excess weight in patients with colorectal cancer}

These six publications represent four RCTs of reasonable methodological quality (mainly Jadad 3) that have been published in the last 10 years, originating from North America, Europe, Australia and Japan (Tables 3 and 4). Three were included in the PA section as they adopted a multiple lifestyle intervention approach, and the same three papers performed their dietary/weight intervention in the adjuvant setting. Study size varied from 91 to 825 with variable recruitment rates (30$78 \%$ ). High retention rates were reported (at least $76 \%$ ), but only one study quoted intervention adherence rates $(>72 \%)$. All aimed to increase dietary quality in the short term, with one study assessing the influence of dietary change on disease-free survival [22, 26, 31, 32, 34, 35].

\section{Specific dietary interventions in colorectal cancer patients}

Only one group has specifically assessed dietary interventions in rectal cancer, finding both short- and long-term patient 
benefits $[34,35]$. Each patient underwent neo-adjuvant chemoradiotherapy for 1.5 months, surgery $3-5$ weeks later, followed by adjuvant chemotherapy. During their radiotherapy, the authors randomised the patients into three groups: group 1 had 6 weeks of individualised nutrition counselling and education sessions using regular foods, group 2 had usual diet with high-protein supplements added in $(40 \mathrm{~g} /$ protein/ day) or group 3 maintenance of usual diet. On completion of radiotherapy, groups 1 and 2 found significant increases in energy and protein intake, but at 3 months, only group 1 documented significant reductions in radiotherapy toxicity and improved nutritional intake/status and QoL. At 5-year follow-up [35], they found that again, only group 1 had a sustained improvement in dietary interventions with $91 \%$ maintaining adequate nutritional status. In addition to higher QoL scores, late radiotherapy toxicity was also significantly lower (9 versus 59\% group 2 versus $65 \%$ group $3 ; p=0.001$ ). However, the most intriguing finding was that both diseasefree survival and disease-specific survival were found to be significantly longer in group 1 after adjustment for age and disease stage (median survival: group 1 with 7.3 years versus group 2 with 6.5 years versus group 3 with 4.9 years; $p<0.01$ ).

\section{Multiple behavioural interventions, including dietary interventions, in colorectal cancer patients}

The next three RCTs performed dietary interventions in the adjuvant setting as part of a multiple behavioural intervention (e.g. physical activity, counselling), which is a pragmatic approach to lifestyle change [22, 26, 31, 32]. The time after diagnosis that the study started recruiting varied from the earliest (12 months) to the latest ( 8 years) with different patient populations in each study (one mixed cancer populations, one colon cancer patients only, one colon and rectal but numbers in each not stated). All interventions were based upon dietary counselling with home-based telephone guidance and reported low dropout rates (0-12\%) with good follow-up rates (77.6 to $89 \%$ ) supporting that these interventions were feasible and well tolerated.

Two of these three studies reported dietary improvement at follow-up [31, 32]. The RENEW Trial reported improved BMI and dietary quality in their older, overweight cancer patients $(n=91)$ [BMI $-0.56 \mathrm{~kg} / \mathrm{m}^{2}(95 \% \mathrm{CI}-0.75$ to -0.36 ; $p<0.001)$; Diet Quality Score 5.2 (95\%CI 3.4 to 7.0 ; $p<0.001)]$. These changes were maintained at the 2 -year follow-up. In addition, their control group underwent similar improved dietary changes when they underwent their delayed intervention 12 months after the intervention group.

CanChange is the largest study in colon cancer patients finding good adherence to their telephone-guided counselling and [26] a significantly reduced BMI at 6 and 12-month follow-up as well as a reduction in fat intake (by $8.5 \%$ at 6 months and $7 \%$ at 12 months; $p=0.001$ and $p=0.006$ ) and increased vegetable intake $(0.4$ servings a day at 6 months; $p=0.001)$. Although this improvement intake seems small, it has the potential to be clinically relevant, as an increase of one portion of fruit and vegetables daily has been shown to reduce cancer.

NC Strides differs from the other two trials as it compared two types of behavioural intervention approaches to modifying lifestyle habits in patients with CRC [22]. TPC consisted of sending out four personalised newsletters. In comparison, TMI participants (telephone motivational interviewing intervention) received four telephone calls with specially trained motivational counsellors. After 1 year, there was a significant increase in fruit and vegetable consumption in the entire study population, but when the CRC patients were separately analysed (healthy controls excluded), there were no significant consumption improvements. One explanation could be selection bias as some participants had been recruited from another trial that had provided dietary advice at its completion.

\section{Discussion}

Current multi-modal treatment pathways for patients with $\mathrm{CRC}$ are individualised, vary in duration and can include major resectional surgery, formation of a stoma, radiotherapy and/or chemotherapy. The challenge for initiating and maintaining lifestyle interventions in this patient group is clear, making it paramount that the feasibility of these trials is established. This systematic review has found that lifestyle interventions on physical activity and/or diet and weight are feasible in patients with colorectal cancer and can be performed peri-operatively, post-operatively and even many years after completion of cancer treatment, with the potential to achieve health benefits. This is the first systematic review to focus on RCTs in a colorectal cancer population, assessing all types of lifestyle interventions, not just one factor, and by including neo-adjuvant and adjuvant interventions [39-42].

Recruitment, intervention adherence and follow-up/retention rates were assessed to allow conclusions to be drawn on feasibility of lifestyle RCTs in CRC patients. Specific conclusions on the recruitment rates are difficult because several studies included other cancer populations, had small numbers of rectal cancer patients, had patients with benign colorectal disease or are, in some cases, not clearly reported. However, in one of the largest RCTs on 410 colon cancer patients, a recruitment rate of $78 \%$ for their multi-factorial lifestyle intervention performed in the adjuvant setting was reported [26]. Furthermore, of the 523 approached, only 5\% declined suggesting that this intervention was attractive for colon cancer patients.

Adherence rates to the intervention were more commonly documented in the PA trials rather than the dietary/weight interventions (where only one RCT documented a rate of 
$>72 \%$ ) [26]. In PA interventions, reasonable adherence rates were reported from 67 to $81.4 \%$. The majority of interventions were home-based telephone interventions rather than regular group-based sessions, which may be why adherence was good as patients could work their PA around their daily routine, including hospital appointments and treatments.

The duration of follow-up for all studies varied according to the study design being as short as 3.8 weeks (prehabilitation study) to a minimum of 5 years. Within this range, follow-up rates vary from 77.6 to $91 \%$, with the majority (9/14) reporting high follow-up rates of over $80 \%$. It is worth highlighting that even the pre-habilitation studies, which had the tightest timeline to perform their PA intervention, had dropout rates of only $10 \%$, supporting the feasibility of prehabilitation $[23,30]$.

As patients with CRC make their way through their treatment pathway, many will experience side effects or significant changes to their health, including fatigue, reduced PA, altered emotional/mental health and reductions in their quality of life. Such changes can be acute, acute-on-chronic or chronic, and although they can exist independently, many cluster together resulting in significant impairment to a patient's short- and long-term recovery [43]. This review has found that dietary/ weight and/or PA interventions have the potential to significantly improve these symptoms, complementing findings that have been reported in other cancer populations [39, 44, 45]. How long these QoL improvements persist for is uncertain with only one dietary intervention assessing and reporting improved long-term outcomes [35].

Improvements in PA and strength measurements were reported in the majority of the 14 RCTs. The range of PA interventions on display, accompanied by a range of aerobic and strength tests, suggests that many types of PA interventions are feasible in CRC patients, but the type, duration and intensity of intervention that optimally improve health remain uncertain, a conclusion that other authors assessing other cancer populations have also drawn [46, 47]. As always, defining the 'optimal intervention' will need to take account of the patient as an individual and his/her's planned oncological treatment pathway, and perhaps several options will need to be made open to allow each patient to select what is suitable for them. In addition, what denotes health will need to be defined, as it means many things to different cancer specialists. For example, surgeons will be interested in pre-habilitation as there is a possibility of 'fitter' patients having shortened length of hospital stay and reduced complications [23, 24]. Oncologists will be interested in reducing side effects and, therefore, improving quality of life as their patients progress through radio- and/or chemotherapy. Everyone, including patients, will be interested in long-term cancer survival, and to date, no RCT on PA intervention has assessed peri-operative or long-term outcomes, making these key areas of research focus. Certainly, it seems achievable to develop minimal recommendations of PA intervention specific to patients with colorectal cancer that are modified to the individual's needs, and it is possible that the international multi-centred Colon Health and Life-Long Exercise Change Trial (CHALLENGE) may provide longterm answers for patients with colon cancer [48].

\section{Limitations of this review}

Of the reviewed papers, none performed interventions on smoking and alcohol, making this an unknown area for patients with CRC. The other area of limitation is that many studies documented recruitment of patients with 'colorectal' cancer. However, the actual numbers of rectal cancer patients were poorly documented with the majority being colonic. Future work should define these different populations and the treatment received. Finally, due to the methodological heterogeneity, a meta-analysis could not be performed.

\section{Conclusion}

This is the first systematic review that has shown that despite the demands of multi-modal treatment pathways for CRC patients, excess weight, dietary and PA interventions are feasible and acceptable in this patient population. With short-term psychological, physical, dietary and weight improvements reported, future trials should focus on optimising lifestyle interventions that integrate with CRC treatment pathways, allowing determination of their potential influence on long-term cancerrelated outcomes.

Acknowledgments The authors would like to acknowledge Nikola Henderson for her help in drafting this article.

\section{Compliance with ethical standards}

Conflict of interest The authors declare no conflicting interests nor was any funding required for this work.

Open Access This article is distributed under the terms of the Creative Commons Attribution 4.0 International License (http:// creativecommons.org/licenses/by/4.0/), which permits unrestricted use, distribution, and reproduction in any medium, provided you give appropriate credit to the original author(s) and the source, provide a link to the Creative Commons license, and indicate if changes were made.

\section{References}

1. Cancer Statistics (2016) Cancer Research UK. http://www. cancerresearchuk.org/health-professional/cancer-statistics/ statistics-by-cancer-type/bowel-cancer/incidence

2. World Cancer Research Fund International (2016) Continuous Update Project Report. Our Cancer Prevention 
Recommendations. http://www.wcrf.org/int/research-we-fund/ourcancer-prevention-recommendations

3. Leitzmann M, Powers H, Anderson AS, Scoccianti C, Berrino F, Boultron-Ruault MC, Cecchini M, Espina C, Ket TJ, Norat T, Wiseman M, Romieu I (2015) European Code against Cancer $4^{\text {th }}$ Edition: physical activity and cancer. Cancer Epidemiol 39(suppl 1):S46-S55

4. Norat T, Scoccianti C, Boutron-Ruault MC, Anderson A, Berrino F, Cecchini M, Espina C, Key T, Leitzmann M, Powers H, Wiseman M, Romieu I (2015) European Code against Cancer $4^{\text {th }}$ Edition: diet and cancer. Cancer Epidemiol 39(suppl 1):S56-S66

5. Anderson AS, Key TJ, Norat T, Scoccianti C, Cecchini M, Berrino F, Boutron-Ruault M-C, Espina C, Leitzmann M, Powers H, Wiseman M, Romieu (2015) European Code against Cancer $4^{\text {th }}$ Edition: obesity, body fatness and cancer. Cancer Epidemiol 39(suppl 1):S34-S45

6. World Health Organisation (2016) International Agency for Research on Cancer Handbook of Cancer Prevention. Weight control and Physical Activity. Volume 6. 2002. http://www.iarc.fr

7. Betof AS, Dewhirst MW, Jones LW (2013) Effects of potential mechanisms of exercise training on cancer progression: a translational perspective. Immunology 30(Suppl 15):S75-S87

8. Bourke L, Homer KE, Thaha MA, Steed L, Rosario DJ, Robb KA, Saxton JM, Taylor SJC (2014) Interventions to improve exercise behaviour in sedentary people living with and beyond cancer: a systematic review. Br J Cancer 110:831-841

9. Rock CL, Doyle C, Demark-Wahnefried W, Meyerhardt J, Courneya KS, Schwartz AL, Bandera EV, Hamilton KK, Grant B, McCullough M, Byers T, Gansler T (2012) Nutrition and physical activity guidelines for cancer survivors. CA Cancer J Clin 62(4):243-274

10. Omish D, Lin J, Chan JM, Epel E, Kemp C, Weidner G, Marlin R et al (2013) Effect of comprehensive lifestyle changes on telomerase activity and telomere length in men with biopsy-proven lowrisk prostate cancer: 5-year follow-up of a descriptive pilot study. Lancet Oncol 14(11):1112-1120

11. Baumann FT, Zopf EM, Bloch W (2012) Clinical exercise interventions in prostate cancer patients: a systematic review of randomized controlled trials. Support Care Cancer 20(2):221-233

12. Hebert JR, Hurley TG, Harmon BE, Heiney S, Hebert CJ, Steck SE (2012) A diet, physical activity and stress reduction intervention in men with rising prostate-specific antigen after treatment for prostate cancer. Cancer Epidemiol 36(2):e128-e136

13. West M, Lythgoe D, Barben CP et al (2014) Cardiopulmonary exercise variables are associated with postoperative morbidity after major colonic surgery: a prospective blinded observational study. Br J Anaesth 112:665-671

14. Trinh L, Mutrie N, Campbell AM, Crawford JJ, Courneya KS (2014) Effects of supervised exercise on motivational outcomes in breast cancer survivors at 5-year follow-up. Eur J Oncol Nurs 18(6): 557-563

15. Moher D, Liberati A, Tetzlaff J, Altman DG (2009) The PRISMA Group Preferred Reporting Items for Systematic Reviews and Meta-Analyses: The PRISMA Statement. PLoS Med. www. prisma-statement.org

16. Cochrane Handbook for Systematic Reviews of Interventions (2011) The Cochrane Collaboration. Version 5.1.0 [updated March 2011]. Available from www.cochrane-handbook.org

17. Schardt C, Adams MB, Owens T, Keitz S, Fontelo P (2007) Utilization of the PICO framework to improve searching PubMed for clinical questions. BMC Med Inform Decis Mak 7[16]

18. Moug S, Bryce A, Mutrie N, Anderson AS (2015) Modifiable lifestyle factors and their influence on colorectal cancer: a systematic review. PROSPERO: CRD42015017205. http://www.crd.york.ac. uk/PROSPERO/display_record.asp?ID=CRD42015017205
19. Jadad AR, Moore RA, Carroll D, Jenkinson C, Reyonolds DJM, Gavaghan DJ, McQuay HJ (1996) Assessing the quality of reports of randomised trials: is blinding necessary? Control Clin Trials 17(1):1-12

20. Moher D, Pham B, Jones A et al (1998) Does quality of reports of randomised trials affect estimates of intervention efficacy reported in meta-analyses? Lancet 352:609-613

21. Adamsen L, Quist M, Andersen C, Moller T, Herrstedt J, Kronberg D, Baadsgaard MT, Vistisen K, Midtgaard J, Christiansen B, Stage M, Kronberg MT, Rorth M (2009) Effect of a multimodal high intensity exercise intervention in cancer patients undergoing chemotherapy: randomised controlled trial. BMJ 339:b3410

22. Campbell MK, Carr C, DeVellis B, Switzer B, Biddle A, Amamoo A, Walsh J, Zhou B, Sandler R (2009) A randomized trial of tailoring and motivational interviewing to promote fruit and vegetable consumption for cancer prevention and control. Ann Behav Med 38(2):71-85

23. Carli F, Charlebois P, Stein B, Feldman L, Zavorsky G, Kim DJ, Scott S, Mayo NE (2010) Randomized clinical trial of prehabilitation in colorectal surgery. Br J Surg 97(8):1187-1197

24. Mayo NE, Feldman L, Scott S et al (2011) Impact of preoperative change in physical function on post-operative recovery: argument supporting prehabilitation for colorectal surgery. Surgery 150:505514

25. Courneya KS, Friedenreich CM, Quinney HA, Fields AL, Jones LW, Fairey AS (2003) A randomized trial of exercise and quality of life in colorectal cancer survivors. European Journal of Cancer Care 12(4):347-357

26. Hawkes AL, Chambers SK, Pakenham KI, Patrao TA, Baade PD, Lynch BM, Aitken JF, Meng X, Courneya KS (2013) Effects of a telephone-delivered multiple health behavior change intervention (CanChange) on health and behavioral outcomes in survivors of colorectal cancer: a randomized controlled trial. J Clin Oncol 31(18):2313-2321

27. Houborg KB, Jensen MB, Rasmussen P, Gandrup P, Schroll M, Laurberg S (2006) Postoperative physical training following colorectal surgery: a randomised, placebo-controlled study. Scand J Surg 95(1): 17-22

28. Houborg KB, Jensen MB, Hessov I, Laurberg S (2005) Little effect of physical training on body composition and nutritional intake following colorectal surgery - a randomised placebo-controlled trial. Eur J Clin Nutr 59(8):969-977

29. Kim DJ, Mayo NE, Carli F, Montogomery DL, Zavorsky GS (2009) Responsive measures to prehabilitation in patients undergoing bowel resection surgery. Tohoku J Exp Med 217(2):109-115

30. Ligibel JA, Meyerhardt J, Pierce JP, Najita J, Shockro L, Campbell N, Newman VA, Barbier L, Hacker E, Wood M, Marshall J, Paskett E, Shapiro C (2012) Impact of a telephone-based physical activity intervention upon exercise behaviors and fitness in cancer survivors enrolled in a cooperative group setting. Breast Cancer Res Treat 132(1):205-213

31. Morey MC, Snyder DC, Sloane R, Cohen HJ, Peterson B, Hartman TJ, Miller P, Mitchell DC, Demark-Wahnefried W (2009) Effects of home-based diet and exercise on functional outcomes among older, overweight long-term cancer survivors: RENEW: a randomized controlled trial. JAMA 301(18):1883-1891

32. Demark-Wahnefried W, Morey MC, Sloane R, Snyder DC, Miller PE, Hartman TJ, Cohen HJ (2012) Reach out to enhance wellness home-based diet-exercise intervention promotes reproducible and sustainable long-term improvements in health behaviors, body weight, and physical functioning in older, overweight/obese cancer survivors. J Clin Oncol 30(19):2354-2361

33. Pinto BM, Papandonatos GD, Goldstein MG, Marcus BH, Farrell N (2013) Home-based physical activity intervention for colorectal cancer survivors. Psycho-Oncology 22(1):54-64 
34. Ravasco P, Monteiro Grillo I, Marques Vidal P, Camilo M (2005) Dietary counseling improves patient outcomes: a prospective, randomized, controlled trial in colorectal cancer patients undergoing radiotherapy. J Clin Oncol 23:1431-1438

35. Ravasco P, Monteiro Grillo I, Camilo M (2012) Individualized nutrition intervention is of major benefit to colorectal cancer patients: long-term follow-up of a randomized controlled trial of nutritional therapy. Am J Clin Nutr 96(6):1346-1353

36. Lynch BM, Courneya KS, Sethi P, Patrao TA, Hawkes AL (2014) A randomized controlled trial of a multiple health behavior change intervention delivered to colorectal cancer survivors: effects on sedentary behaviour. Cancer 120(17):2265-2672

37. Kehlet H, Wilmore DW (2008) Evidence-based surgical care and the evolution of fast-track surgery. Ann Surg 248:189-198

38. (2010) Physical Activity Guidelines in the UK: Review and Recommendations. https://www.gov.uk/government/uploads/ system/uploads/attachment data/file/213743/dh 128255.pdf

39. Schmitz KH, Holtzman J, Courneya KS, Masse LC, Duval S, Kane R (2005) Controlled physical activity trials in cancer survivors: a systematic review and meta-analysis. Cancer Epidemiol Biomark Prev 14(7):1588-1595

40. Goode AD, Lawler SP, Brakenridge CL, Reeves MM, Eakin EG (2015) Telephone, print and web-based interventions for physical activity, diet and weight control among cancer survivors: a systematic review. J Cancer Surviv 9(4):660-682
41. Friedenriech CM, Neilson HK, Farris MS, Courneya KS (2016) Physical activity and cancer related outcomes: a precision medicine approach. Clin Cancer Res 22(19):4766-4775

42. Loughney L, West MA, Kemp GJ, Grocott MPW, Jack S (2016) Exercise intervention in people with cancer undergoing adjuvant cancer treatment following surgery: a systematic review. EJSO 41(12):1590-1602

43. Mustian KM, Cole CL, Lin PJ et al (2016) Exercise recommendations for the management of symptoms cluster resulting from cancer and cancer treatments. Semin Oncol Nurs 32(4):383-393

44. Hayes BD, Brady L, Pollak M, Finn SP (2016) Exercise and prostate cancer: evidence and proposed mechanisms for disease modification. Cancer Epidemiol Biomark Prev 25(9):1281-1288

45. Mutrie N, Campbell AM, Whyte F, McConnachie A et al (2007) Benefits of supervised group exercise programme for women being treated for early stage breast cancer: pragmatic randomised controlled trial. BMJ 334(7592):517

46. Buffart LM, Galvao DA, Brug J, Chinapaw MJM, Newton RU (2014) Evidence-based physical activity guidelines for cancer survivors: current guideline, knowledge gaps and future research directions. Cancer Treat Rev 40:327-340

47. World Health Organisation (2016) Global strategy on diet, physical activity and health. http://www.who.int/dietphysicalactivity/en/

48. Courneya KS, Booth CM, Gill S et al (2008). The Colon Health and Life-Long Exercise Change trial: a randomized trial of the National Cancer Institute of Canada Clinical Trials Group. Curr Oncol, 15 (6) 